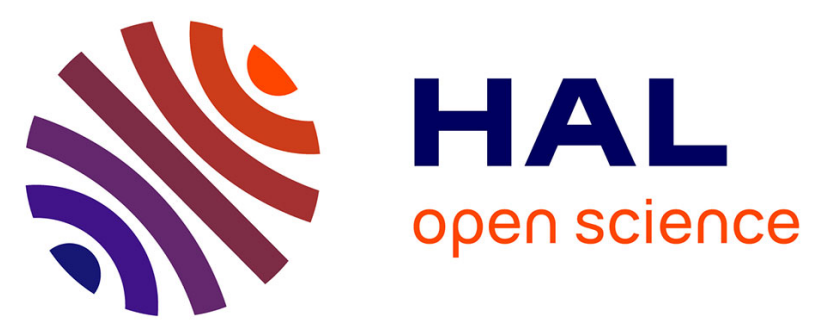

\title{
Glycosylation of human plasma lipoproteins reveals a high level of diversity, which directly impacts their functional properties
}

Vasily Sukhorukov, Ivan Gudelj, Maja Pučić-Baković, Emile Zakiev, Alexander Orekhov, Anatol Kontush, Gordan Lauc

\section{To cite this version:}

Vasily Sukhorukov, Ivan Gudelj, Maja Pučić-Baković, Emile Zakiev, Alexander Orekhov, et al.. Glycosylation of human plasma lipoproteins reveals a high level of diversity, which directly impacts their functional properties. Biochimica et Biophysica Acta Molecular and Cell Biology of Lipids, 2019, 1864 (5), pp.643-653. 10.1016/j.bbalip.2019.01.005 . hal-02135945

\section{HAL Id: hal-02135945 \\ https://hal.sorbonne-universite.fr/hal-02135945}

Submitted on 27 Jun 2019

HAL is a multi-disciplinary open access archive for the deposit and dissemination of scientific research documents, whether they are published or not. The documents may come from teaching and research institutions in France or abroad, or from public or private research centers.
L'archive ouverte pluridisciplinaire HAL, est destinée au dépôt et à la diffusion de documents scientifiques de niveau recherche, publiés ou non, émanant des établissements d'enseignement et de recherche français ou étrangers, des laboratoires publics ou privés. 
Glycosylation of human plasma lipoproteins reveals a high level of diversity, which directly impacts their functional properties

Vasily Sukhorukov, MSc ${ }^{\text {a,b,c }}$, Ivan Gudelj, $\mathrm{PhD}{ }^{\mathrm{d}}$, Maja Pučić-Baković, PhD ${ }^{\mathrm{d}}$, Emile Zakiev, $\mathrm{MSc}^{\mathrm{a}, \mathrm{b}, \mathrm{c}}$, Alexander Orekhov PhD, DSc ${ }^{\mathrm{a}, \mathrm{e}}$, Anatol Kontush, PhD ${ }^{\mathrm{b}^{*}}$, Gordan Lauc, PhD ${ }^{\mathrm{d}}$

${ }^{a}$ Laboratory of Angiopathology, Institute of General Pathology and Pathophysiology, 125315 Moscow, Russia

${ }^{\mathrm{b}}$ National Institute for Health and Medical Research (INSERM), UMR 1166 ICAN, Paris F75013 France; University of Pierre et Marie Curie - Paris 6, Paris, F-75013 France; AP-HP, Groupe hospitalier Pitié-Salpétrière, Paris, F-75013 France

${ }^{c}$ Federal State Budget Institution of Sciences Institute of Gene Biology, Russian Academy of Sciences, Vavilova Str., 34/5, Moscow, 119334 Russia

${ }^{\mathrm{d}}$ Genos Glycoscience Research Laboratory, Borongajska cesta 83H, HR-10 000 Zagreb, Croatia

${ }^{\mathrm{e}}$ Institute for Atherosclerosis Research, Skolkovo Innovative Center, 121609 Moscow, Russia

Corresponding author: *Dr. Anatol Kontush, INSERM UMR_S 1166 - ICAN, Faculté de Médecine Pitié-Salpêtrière, 91, Bd de l'Hôpital, 75013 Paris, France. Tel. (33) (1) 40779633. Fax (33) (1) 407796 45. E-mail anatol.kontush@upmc.fr 
Abstract:

Aims Human plasma lipoproteins are known to contain various glycan structures whose composition and functional importance are starting to be recognized. We assessed $\mathrm{N}$ glycosylation of human plasma HDL and LDL and the role of their glycomes in cellular cholesterol metabolism.

Methods N-glycomic profiles of native and neuraminidase-treated HDL and LDL were obtained using HILIC-UHPLC-FLD. Relative abundance of the individual chromatographic peaks was quantitatively expressed as a percentage of total integrated area and $\mathrm{N}$-glycan structures present in each peak were elucidated by MALDI-TOF MS. The capacity of HDL to mediate cellular efflux of cholesterol and the capacity of LDL to induce cellular accumulation of cholesteryl esters were evaluated in THP-1 cells.

Results HILIC-UHPLC-FLD analysis of HDL and LDL N-glycans released by PNGase F resulted in 22 and 18 distinct chromatographic peaks, respectively. The majority of N-glycans present in HDL $(\sim 70 \%)$ and LDL $(\sim 60 \%)$ were sialylated with one or two sialic acid residues. The most abundant N-glycan structure in both HDL and LDL was a complex type biantennary $\mathrm{N}$-glycan with one sialic acid (A2G2S1). Relative abundances of several N-glycan structures were dramatically altered by the neuraminidase treatment, which selectively removed sialic acid residues. Native HDL displayed significantly greater efficacy in removing cellular cholesterol from THP-1 cells as compared to desialylated HDL $(\mathrm{p}<0.05)$. Cellular accumulation of cholesteryl esters in THP-1 cells was significantly higher after incubations with desialylated LDL particles as compared to native LDL $(\mathrm{p}<0.05)$.

Conclusions N-glycome of human plasma lipoproteins reveals a high level of diversity, which directly impacts functional properties of the lipoproteins.

Keywords: glycome, high-density lipoprotein, low-density lipoprotein, sialic acid, cholesterol efflux, cholesterol accumulation 


\section{Introduction}

Atherosclerosis is a disease of large- and medium-sized arteries that starts with the accretion of lipids in the arterial wall. Low-density lipoprotein (LDL) represents the major source of the lipids [1], while high-density lipoprotein (HDL) possesses multiple antiatherogenic activities, which primarily involve efflux of intracellular cholesterol in the process of reverse cholesterol transport (RCT) [2, 3].

In addition to lipids and proteins, lipoproteins contain carbohydrates as a minor component. Indeed, HDL contains $3.3 \mathrm{wt} \%$ of carbohydrates [4], and LDL apolipoprotein (apo) B carries $4.4 \mathrm{wt} \%$ of them [5]. Sialic acids are present in LDL as terminal carbohydrates of biantennary carbohydrate chains in apoB and of carbohydrate chains in gangliosides [6, 7]. Similarily to LDL, HDLs are highly sialylated particles in which most of the glycans contain one or two sialic acid residues [8].

The lipoprotein glycome can be altered in disease. Desialylation of LDL by neuraminidases (sialidases) and other glycoside hydrolases may occur in vivo under normal and, particularly, under pathological conditions [9]. As a result, sialic acid content is diminished in LDL isolated from plasma of patients with cardiovascular disease (CVD) and Type 2 diabetes relative to LDL from healthy donors [10-13]. Moreover, atherogenic immune complexes present in the circulation contain LDL that display modifications similar to those found in desialylated LDL [14]. When administered to a primary culture of human aortic intimal cells or to a culture of human monocyte-derived macrophages, desialylated LDL induce intracellular cholesterol accumulation $[10,13,15,16]$. Native LDL desialylated with neuraminidase in vitro reveal similar biological activity $[17,18]$.

LDL can undergo in vivo modifications by glyco-oxidation [19], glycation [20], oxidation [21], and desialylation [22] that increase LDL atherogenicity. Such modified LDL is taken up by macrophages through scavenger receptors, leading to the formation of foam cells. More specifically, uptake of desialylated LDL by human and mouse macrophages can be mediated by 
both scavenger receptors [13] and galactose-specific lectin receptors which recognize terminal galactose residues of LDL exposed after desialylation [23].

HDL desialylation may be similarly proatherogenic, diminishing both HDL-promoted cellular cholesterol efflux and cholesteryl esterification rate mediated by lecithin-cholesterol acyltransferase (LCAT) [24]. Desialylated HDL might be internalized via scavenger receptors without provoking cholesteryl ester accumulation in macrophages [17]. Furthermore, desialylation of apolipoprotein $\mathrm{E}$ (apoE), a protein HDL component, decreases its binding to HDL, potentially leading to impaired RCT function [25]. Interestingly, patients with coronary artery disease (CAD) display distinct HDL glycosylation pattern that distinguishes them from non-CAD controls [26]. Similar differences were found between patients with metabolic syndrome and healthy subjects [27]. Furthermore, HDL glycoprotein composition differentiates between clinical groups, correlating with immunomodulatory capacity of HDL [28]. Remarkably, carbohydrate residues are specifically associated with distinct HDL proteins, such as apo C-III which contains O-linked glycans [29].

Together, these data suggest that the glycome may play a key role for biological properties of LDL and HDL. In order to evaluate this hypothesis, we characterized the Nglycome of human LDL and HDL by matrix-assisted laser desorption/ionization time-of-flight mass spectrometry (MALDI-TOF MS) and evaluated its role in the capacity of HDL to mediate cellular efflux of cholesterol and in the capacity of LDL to induce cellular accumulation of cholesteryl esters in macrophage-like human THP-1 cells. Here we report that both LDL and HDL possess a highly diverse glycome and that the absence of terminal sialic acids reduces antiatherogenic properties of HDL and enhances pro-atherogenic properties of LDL. 


\section{Materials and Methods}

\section{Subjects}

Twelve normolipidemic healthy non-obese male volunteers were recruited for the study. All subjects were between 32 and 67 years of age, non-smokers, and either abstainers or moderate alcohol consumers $(<25 \mathrm{~g} / \mathrm{d})$. None of the subjects presented renal, hepatic, gastrointestinal, pulmonary, endocrine, or oncological disease nor were receiving drugs known to affect lipoprotein metabolism for at least 6 weeks before the study. The null hypothesis stated that biological activities of lipoproteins are not modified by glycome modifications. A sample size of 6 subjects was calculated in order to detect significant differences of $25 \%$ in the biological activities following glycome modifications at the variation level of $10 \%$, statistical power of $90 \%$ and alpha of 0.05 . All subjects gave written informed consent and the study was performed in accordance with local institutional guidelines conformed to the Declaration of Helsinki.

\section{Blood samples}

Blood samples were withdrawn from the cubital vein of each participant at the time of recruitment. EDTA plasma (final EDTA concentration, $1 \mathrm{mg} / \mathrm{ml}$ ) were prepared from venous blood collected into sterile, evacuated tubes (Vacutainer). Plasma was immediately separated by low-speed centrifugation at $4{ }^{\circ} \mathrm{C}$, mixed with sucrose (final concentration, $0.6 \%$ ) as a cryoprotectant for lipoproteins [30], aliquoted and frozen at $-80{ }^{\circ} \mathrm{C}$ under nitrogen; each aliquot was thawed only once directly before analyses.

\section{Isolation of lipoproteins}

Lipoproteins were isolated from plasma by single step, isopycnic, non-denaturing density gradient ultracentrifugation in a Beckman SW41 Ti rotor at 40,000 rpm for 44 hours in a Beckman XL70 ultracentrifuge at $15{ }^{\circ} \mathrm{C}$ by a slight modification of the method of Chapman et 
al. [31] as described previously [32]. After centrifugation, each gradient was fractionated in predefined volumes from the meniscus downwards with an Eppendorf precision pipette into 11 fractions corresponding to VLDL+IDL (d<1.019 g/mL), LDL (five subfractions, LDL1, d 1.019$1.023 \mathrm{~g} / \mathrm{mL}$; LDL2, d 1.023-1.029 g/mL; LDL3, d 1.029-1.039 g/mL; LDL4, d 1.039-1.050 $\mathrm{g} / \mathrm{mL}$; and LDL5, d 1.050-1.063 g/mL) and HDL (five subfractions, large, light HDL2b, d $1.063-1.087 \mathrm{~g} / \mathrm{ml}$, and HDL2a, d 1.088-1.110 g/ml, and small, dense HDL3a, d 1.110-1.129 $\mathrm{g} / \mathrm{ml}$, HDL3b, d 1.129-1.154 g/ml, and HDL3c, d 1.154-1.170 g/ml). All LDL subfractions and HDL subfractions were pooled to obtain total LDL and HDL, respectively. The validity and reproducibility of this density gradient procedure, which facilitates preparative fractionation of lipoproteins in a non-denaturated, native state, have been extensively documented [31, 33]. Lipoproteins were extensively dialysed against phosphate-buffered saline (PBS; pH 7.4) at $4{ }^{\circ} \mathrm{C}$ in the dark, stored at $4{ }^{\circ} \mathrm{C}$ and used within 10 days, or frozen at $-80{ }^{\circ} \mathrm{C}$ for analytical measurements.

\section{Chemical analysis and enzymatic activity of lipoproteins}

Total protein, total cholesterol (TC), free cholesterol (FC), phospholipid (PL) and triglyceride (TG) contents of isolated lipoproteins were determined using commercially available assays $[31,34]$. Cholesteryl ester (CE) was calculated by multiplying the difference between total and free cholesterol concentrations by 1.67 [31]. Total lipoprotein mass was calculated as the sum of total protein, CE, FC, PL and TG. When the lipoprotein components were expressed as their absolute plasma concentration or as a percentage of total lipoprotein mass, chemical composition of HDL and LDL was consistent with earlier reports [34, 35] (data not shown).

LCAT activity of HDL was measured using a commercially available fluorescent kit for plasma LCAT activity from Roar Biochemical (New York, NY, USA) that evaluates accumulation of free cholesterol in the samples. The protocol was modified to include in the assay an amount of HDL similar to that employed in the measurement of LCAT activity in 
plasma. More specifically, a fixed amount of HDL protein of $50 \mu \mathrm{g}$ was mixed with reagents according to the manufacturer's instructions. The coefficient of variation of the assay was $2.4 \%$.

\section{Heterogeneity and mean size of $H D L$}

The heterogeneity of HDL was evaluated by native PAGE using precasted $4-12 \%$ gradient gels from Invitrogen (France) according to the manufacturer's instructions. This approach allowed detecting lipid-free/lipid-poor apoA-I by Western blotting and calculating mean HDL size as described elsewhere [36]. Briefly, $15 \mu \mathrm{g}$ of HDL protein or $5 \mu \mathrm{g}$ of lipid-free ApoA-I were applied to NuPAGE Tris-acetate 4-12\% gels (Invitrogen, CA, USA) and the gels were run for $3 \mathrm{~h}$ at $150 \mathrm{~V}$ in the MOPS buffer according to the manufacturer's instructions. Following the transfer to nitrocellulose, goat anti-human apoA-I antibody (Merck) and donkey anti-goat IRDye $800 \mathrm{CW}$ antibody (LI-COR, Lincoln, NE, USA) were used as a primary and secondary antibody, respectively, to detect apoA-I.

The mean HDL size was calculated using the PageRuler Broad Range Unstained Protein Ladder as a calibration (Thermo Scientific, USA). Gels were scanned using Odyssey Imaging System for Western blots and gel imaging (LI-COR, Lincoln, NE, USA) and the mean position of each peak was identified using the system's software.

\section{Glycomic profiling of lipoproteins}

Prior to deglycosylation, lipoprotein samples were desalted using ice-cold methanol (Merck, Darmstadt, Germany). Briefly, dried lipoprotein samples were resuspended in $1 \mathrm{~mL}$ of ice-cold methanol and centrifuged for $15 \mathrm{~min}$ at $2200 \mathrm{~g}$. The supernatant was carefully removed and the procedure was repeated. The remaining methanol was evaporated by drying down in the vacuum concentrator.

Dried samples were dissolved in $30 \mu \mathrm{L}$ of $1.33 \%$ SDS (w/v) and denatured by incubation at $65{ }^{\circ} \mathrm{C}$ for 10 minutes. The following steps of $\mathrm{N}$-glycan release and fluorescent labelling were essentially as described recently [37]. After labelling, the free label and reducing agent were 
removed from the samples by hydrophilic interaction liquid chromatography solid-phase extraction (HILIC-SPE) using $0.2 \mu \mathrm{m}$ GHP filter plates and ice-cold 96\% acetonitrile [37].

Fluorescently labelled N-glycans were separated by hydrophilic-interaction ultra-highperformance liquid chromatography with fluorescence detection (HILIC-UHPLC-FLD) on a Waters Acquity UHPLC H-class system (Milford, MA, USA) as described previously [37]. Briefly, labelled N-glycans were separated on a Waters BEH Glycan chromatography column, $150 \times 2.1 \mathrm{~mm}$ i.d., $1.7 \mu \mathrm{m}$ BEH particles, with $100 \mathrm{mM}$ ammonium formate, $\mathrm{pH} 4.4$, as solvent A and acetonitrile as solvent B. Separation method used linear gradient of 70-53\% acetonitrile $(\mathrm{v} / \mathrm{v})$ at flow rate of $0.56 \mathrm{ml} / \mathrm{min}$ in a 23 minute analytical run. Samples were maintained at 10 ${ }^{\circ} \mathrm{C}$ before injection, and the separation temperature was $25^{\circ} \mathrm{C}$. The chromatograms obtained were all separated in the same manner into 22 and 18 chromatographic peaks for HDL and LDL, respectively, and the abundance of glycans in each peak was expressed as \% of total integrated area.

The identity of N-glycans separated by HILIC-UHPLC-FLD was determined by MALDITOF-MS. Prior to MS analysis, fractions of each N-glycan chromatography peak were collected, dried down in a vacuum concentrator, resuspended in $10 \mu \mathrm{L}$ of ultrapure water and stabilized by ethyl esterification as previously described [38]. Aliquots of $2 \mu \mathrm{L}$ were spotted onto a MTP AnchorChip 384 BC MALDI target (Bruker Daltronics, Bremen, Germany), mixed on plate with $1 \mu \mathrm{L}$ of matrix solution ( $5 \mathrm{mg} / \mathrm{mL} 2,5-\mathrm{DHB}, 1 \mathrm{mM} \mathrm{NaOH}$ in $50 \%$ acetonitrile) and left to dry by air. Recrystallization was performed by adding $0.2 \mu \mathrm{L}$ of ethanol to each spot. Analyses were performed in positive-ion reflectron mode on an UltrafleXtreme MALDI-TOF-MS equipped with a Smartbeam-II laser and FlexControl 3.4 software Build 119 (Bruker Daltonics). The instrument was calibrated using a plasma $\mathrm{N}$-glycome standard. A $25 \mathrm{kV}$ acceleration voltage was applied after a $140 \mathrm{~ns}$ extraction delay. A mass window of m/z 1000 to 5000 with suppression up to $\mathrm{m} / \mathrm{z} 900$ was used for N-glycan samples. For each spectrum, 10000 laser shots were 
accumulated at a laser frequency of $2000 \mathrm{~Hz}$, using a complete sample random walk with 200 shots per raster spot.

\section{Desialylation of lipoproteins}

Total LDL and HDL prepared by mixing all LDL and HDL subfractions, respectively, at their equivalent serum concentrations were incubated in the absence (controls) and presence of neuraminidase (final concentration $0.1 \mathrm{U}$ enzyme/mg protein; GlycoCleave ${ }^{\circledR}$ Neuraminidase EnzymeBeads, Galab, Germany) in sodium acetate buffer (final concentration $50 \mathrm{mM}$ NaAc, 1 $\mathrm{mM} \mathrm{CaCl} 2$, pH 6,0) under shaking for 16 hours at $37^{\circ} \mathrm{C}$. At the end of the incubation the enzyme beads were removed from the samples by ultracentrifugation at 1,000 rpm for 5 minutes.

In some experiments, neuraminidase-treated HDL was subsequently incubated with betagalactosidase (New England Biolabs, USA) overnight at $37{ }^{\circ} \mathrm{C}$ under constant shaking. Native HDL was also treated with PNGase F (New England Biolabs, USA) overnight at $37{ }^{\circ} \mathrm{C}$ under constant shaking.

Cellular cholesterol efflux capacity of $H D L$

The cholesterol efflux capacity of total HDL was characterised in a human THP-1 monocytic cell system (ATCC, Manassas, VA, USA), THP-1 cells with stably silenced ABCA1 gene and THP-1 cells with silenced SCARB1 gene (human SR-BI) at $30 \mu \mathrm{g}$ HDL PL/ml [39]. HDL particles were compared on the basis of their PL concentrations because PL was shown to represent the key component determining cholesterol efflux capacity of HDL [40].

Assays of cellular cholesterol efflux were performed as previously described [41] with minor modifications. In brief, THP-1 monocytes were cultured on 24-well tissue culture plates, grown in RPMI (Roswell Park Memorial Institute medium) 1640 media with $10 \%$ fetal bovine serum (FBS) and differentiated into macrophage-like cells with $50 \mathrm{ng} / \mathrm{ml}$ phorbol 12 -myristate 13-acetate (PMA) for 48 hours and $37{ }^{\circ} \mathrm{C}$. The cells were washed and loaded for $24 \mathrm{~h}$ with $\left[{ }^{3} \mathrm{H}\right]$ cholesterol-labelled acetylated LDL (acLDL, $1 \mu \mathrm{Ci} / \mathrm{mL}$ ) in serum-free RPMI 1640 culture 
medium supplemented with $50 \mathrm{mM}$ glucose, $2 \mathrm{mM}$ glutamine, $0.2 \% \mathrm{BSA}, 100 \mu \mathrm{g} / \mathrm{ml}$ penicillin and $100 \mu \mathrm{g} / \mathrm{ml}$ streptomycin (further abbreviated as RGGB). The labelling medium was removed and human macrophages were incubated in RGGB for an additional 16-24 h period to allow cells to equilibrate their metabolic processes. Cellular cholesterol efflux was assayed in serum-free medium for a 4-hour chase period. Finally, culture media were harvested and cleared of cellular debris by brief centrifugation. Cell radioactivity was determined by extraction in hexaneisopropanol (3:2), evaporation of the solvent under nitrogen and liquid scintillation counting (Wallac Trilux 1450 Microbeta, Perkin Elmer, USA). The percentage of cholesterol efflux was calculated as (medium cpm) / (medium cpm + cell cpm) x 100\%. Specific cholesterol efflux was determined by subtracting non-specific cholesterol efflux occurring in the absence of cholesterol acceptors.

Silencing of ABCA1 and SCARB1 in THP-1 cells

Silencing of $A B C A 1$ in THP-1 cells was achieved by transfection with a SureSilencing shRNA plasmid (Clone ID 1, Cat.KH02595P, SABiosciences) [39]. Monoclonal THP-1$\triangle \mathrm{ABCA} 1 \mathrm{cell}$ lines were selected with puromycin $(250 \mathrm{ng} / \mathrm{ml})$ and knockdown of $A B C A 1$ was confirmed by Western blot. For all experiments THP-1 cells were seeded at $10^{6}$ cells $/ 16 \mathrm{~mm}$ diameter well and were differentiated for $72 \mathrm{~h}$ in RPMI with $10 \%$ heat-inactivated fetal calf serum and phorbol 12-myristate 13-acetate (PMA; 50 ng/ml, Sigma).

Silencing of SCARB1 in THP-1 cells was achieved by transfection with $50 \mathrm{nM}$ SCARB1 siRNA or negative control (scramble sequence, Dharmacon, Thermo Fisher Scientific MA, USA) using Lipofectamine RNAiMax (Invitrogen, CA, USA) according to the manufacturer's instruction. Cells were incubated during 8 hours, washed with PBS and then incubated during 24 hours in fresh media. Cell transfection was confirmed by RT-PCR.

\section{Cellular cholesterol accumulation induced by $L D L$}

THP-1 monocytes were cultured on 24-well tissue culture plates, grown in RPMI 1640 media with $10 \%$ FBS and differentiated into macrophage-like cells with $50 \mathrm{ng} / \mathrm{ml}$ phorbol 12 - 
myristate 13-acetate (PMA) for 48 hours and $37{ }^{\circ} \mathrm{C}$. The cells were washed and loaded for $48 \mathrm{~h}$ with desialylated LDL $(100 \mu \mathrm{g}$ protein/mL), or with native LDL $(100 \mu \mathrm{g}$ protein/mL) as a control, in serum-free RPMI 1640 culture medium supplemented with RGGB to allow equilibration of cellular metabolic processes. Control cells were prepared under identical conditions but without addition of LDL. Total cholesterol content of the THP-1 cells was determined by the Amplex Red cholesterol assay at the end of the incubations.

\section{Statistical analysis}

Distributions of all variables were analysed for normality using the Kolmogorov-Smirnov test. Normally-distributed variables are expressed as means $\pm \mathrm{SD}$; non-Gaussian distributed variables are expressed as median (minimum, maximum). Between-group differences in normally-distributed variables were analyzed using the Student's t-test. For non-Gaussian distributed variables, the Mann-Whitney U-test was used. Spearman's correlation coefficients were calculated to evaluate relationships between variables. Statistical analyses were performed using Statistica 6.1 software package (StatSoft France, Maisons Alfort, France). 


\section{Results}

Glycomic profiling of $L D L$ and $H D L$

HILIC-UHPLC-FLD analysis of HDL (Fig. 1, A) and LDL (Fig. 1, B) N-glycans released after PNGase F treatment resulted in 22 and 18 distinct chromatographic peaks, respectively. Relative abundance of the peaks representing $\mathrm{N}$-glycans was quantitatively assessed as a percentage of total integrated area. Identities of $\mathrm{N}$-glycan structures present in each peak were determined by MALDI-TOF MS after ethyl esterification which chemically modifies sialylated glycans enabling distinction between $\alpha 2,3-$ and $\alpha 2,6$-linked sialic acids. The list of the most abundant HDL and LDL N-glycans in each peak with their $\mathrm{m} / \mathrm{z}$ values, monosaccharide composition and proposed structures are given in Table 1 and Table 2, respectively. More than 20 glycan structures were characterized in both HDL and LDL, including complex, highmannose and hybrid N-glycans. Most of the N-glycans present in HDL ( 70\%) and LDL ( $60 \%)$ were complex sialylated structures with one or two sialic acid residues. The most abundant HDL N-glycans were mono- and disialylated biantennary structures, A2G2S1 and A2G2S2. Similarly, A2G2S1 was the most abundant $\mathrm{N}$-glycan in the LDL N-glycome, but in contrast to HDL, LDL revealed much higher prevalence of high-mannose $\mathrm{N}$-glycans ( $33 \%$ vs. $\sim 3 \%)$.

Treatment of HDL and LDL with neuraminidase, which selectively removes $\mathrm{N}$ acetylneuraminic acid (sialic acid) residues, dramatically altered their N-glycomic profiles (Fig. 2, A and B). Notably, relative abundance of peaks representing sialylated structures was decreased upon the treatment (e.g. $\mathrm{GP}_{\mathrm{HDL}} 13$ and $\mathrm{GP}_{\mathrm{HDL}} 15$ ) while the abundance of peaks representing corresponding desialylated structures was increased (e.g. $\mathrm{GP}_{\mathrm{HDL}} 7$ and $\mathrm{GP}_{\mathrm{HDL}} 8$; Fig. 3, A). Similarly, LDL peak $\mathrm{GP}_{\mathrm{LDL}} 6$ was increased, reflecting decrease of peaks $\mathrm{GP}_{\mathrm{LDL}} 13$ and GP $_{\text {LDL }} 15$ (Fig. 3, B). This change in the relative abundance of sialylated N-glycans upon neuraminidase treatment was less evident in the case of $\mathrm{GP}_{\mathrm{HDL}} 10$ and $\mathrm{GP}_{\mathrm{LDL}} 10$ representing their most abundant $\mathrm{N}$-glycan, A2G2S1, since besides causing a decrease in their abundances by shifting desialylated form of A2G2S1 to earlier elution times ( $\mathrm{GP}_{\mathrm{HDL}} 7$ and $\left.\mathrm{GP}_{\mathrm{LDL}} 6\right)$, 
neuraminidase treatment also caused an increase in their abundances by shifting desialylated forms of triantennary $\mathrm{N}$-glycans to elute at the retention time of $\mathrm{GP}_{\mathrm{HDL}} 10$ and $\mathrm{GP}_{\mathrm{LDL}} 10$ (e.g. A3G2S2 from $\mathrm{GP}_{\mathrm{HDL}} 17$ shifted to $\mathrm{GP}_{\mathrm{HDL}} 10$ after the desialylation).

\section{Cellular cholesterol efflux capacity of HDL}

The capacity of native and desialylated HDL particles to mediate cellular efflux of cholesterol was evaluated in macrophage-like human THP-1 cells, which efflux cholesterol predominantly via the ABCA1-dependent pathway. Native HDL displayed significantly greater efficacy $(+16 \%)$ in removing cellular cholesterol as compared to desialylated HDL particles $(8.62 \pm 1.44 \%$ for native vs $7.21 \pm 1.00 \%$ for neuraminidase-treated, $\mathrm{p}<0.05$, Fig. 4, A). By contrast, there was no significant difference in the capacity of native and desialylated HDL particles to remove cholesterol from human THP-1 cells in which SCARBI expression was knocked-down $(6.57 \pm 0.39 \%$ vs. $6.09 \pm 0.47 \%$, respectively; $p>0.05)$. Similarly, differences in cholesterol efflux capacity of native and desialylated HDL were absent in $A B C A 1-/-$ macrophagic cells $(4.19 \pm 0.18 \%$ vs. $4.48 \pm 0.46 \%$, respectively; $p>0.05)$.

When HDL was treated with beta-galactosidase following the treatment with neuraminidase, no further reduction in the cholesterol efflux capacity was observed (Fig. 4, B). A single treatment with PNGase F significantly diminished cholesterol efflux capacity of HDL (Fig; 4, B).

Heterogeneity, mean size and LCAT activity of HDL

When HDL subpopulations were separated using native PAGE and apoA-I was detected by Western blotting, no release of the lipid-free/lipid-poor apoA-I from desialylated HDL was observed (Supplement Figure). Interestingly, the mean HDL size was slightly but significantly reduced from $9.5 \pm 0.1$ to $9.0 \pm 0.1 \mathrm{~nm}(-5.3 \%, \mathrm{p}<0.01, \mathrm{n}=3)$ by the desialylation. 
LCAT activity was markedly decreased (by -46\%) after the desialylation as compared to HDL samples incubated in parallel in the absence of neuraminidase $(925 \pm 412$ vs. $1702 \pm 442$ $\mathrm{nmol} / \mathrm{h} / \mathrm{ml}$, respectively; $\mathrm{p}=0.10, \mathrm{n}=3)$.

\section{Cellular cholesteryl ester accumulation induced by $L D L$}

When native and desialylated LDL particles were incubated with macrophage-like human THP-1 cells, cellular accumulation of cholesteryl esters was significantly higher (2.7-fold) after incubation with desialylated LDL as compared to incubations with native LDL $(0.0242 \pm 0.0125 \%$ vs $0.0090 \pm 0.0045 \%$, respectively; p<0.05, Fig. $4, \mathrm{C})$.

\section{Relationships between the N-glycome and biological properties of LDL and HDL}

Series of significant correlations were observed between N-glycomic composition and cellular cholesterol efflux capacity of HDL (Fig. 5, A and C; Table 3). In native HDL samples, positive correlations were calculated for the peaks containing mono- and disialylated N-glycans $\left(\mathrm{GP}_{\mathrm{HDL}} 11\right.$ and 13), while the level of a high-mannose N-glycan, M9 (GP $\left.\mathrm{HDL}_{14}\right)$ negatively correlated with HDL efflux capacity. Similarly, in neuraminidase-treated HDL samples, levels of high-mannose and hybrid $\mathrm{N}$-glycans $\left(\mathrm{GP}_{\mathrm{HDL}} 2,6\right.$ and 14) showed negative correlations with the efflux, while complex biantennary $\left(\mathrm{GP}_{\mathrm{HDL}} 8\right)$ and triantennary $\left(\mathrm{GP}_{\mathrm{HDL}} 22\right) \mathrm{N}$-glycans revealed a positive correlation.

As for the relationship between LDL N-glycomic profile and capacity to induce cellular cholesterol accumulation, only one significant correlation was found (Fig. 5, B and C; Table 4). Notably, the peak GP $\mathrm{LDL}_{16}$, representing sialylated N-glycan A3G3S2, was positively correlated with LDL capacity to induce cholesterol accumulation. 


\section{Discussion}

In this study, we assessed N-glycosylation of native human plasma HDL and LDL using HILIC-UHPLC-FLD and MALDI-TOF MS. The N-glycome of both HDL and LDL revealed a high level of diversity, reflected in the presence of complex, high-mannose and hybrid $\mathrm{N}$ glycans. We showed that HDL and LDL are highly sialylated particles, consistent with earlier reports $[8,42]$.

In our study, the most abundant HDL N-glycans were biantennary complex type $\mathrm{N}$ glycans with one and two sialic acid residues. In this regard, HDL is similar to other glycoproteins of human plasma, which are rich in biantennary complex type $\mathrm{N}$-glycans [43]. In a similar fashion, a biantennary complex type glycan A2G2S2 containing two sialic acid residues was recently reported to represent the most abundant glycan in HDL, followed by a glycan with a single sialic acid residue [8]. While our present studies identified A2G2S1 as the major HDL glycan, this subtle difference may reflect different methodologies employed to isolate HDL or variations in analytical and/or experimental conditions [44].

Similarly to HDL, the most abundant LDL N-glycan was A2G2S1 but in contrast to HDL, the LDL N-glycome was also found to be rich in high-mannose (M5-M9) structures. Consistent with this data, a high level of high-mannose N-glycans was reported for apoB [45], a primary protein component of LDL. After the treatment of HDL and LDL with neuraminidase, the proportions of individual $\mathrm{N}$-glycans were altered, reflecting removal of sialic acids.

The majority of proteins secreted in the circulation are glycosylated. Sialic acids are Nand $\mathrm{O}$-acyl derivatives of neuraminic acid that are typically found at the terminus of $\mathrm{N}$ - and $\mathrm{O}$ glycans [46]. Sialic acids increase electronegativity of glycoproteins [47] and display a number of biological activities, acting as a ligand [48], as a biological mask that covers sub-terminal galactose residues [47], and as a regulator of protein retention in the circulation [49]. Increased levels of free sialic acid are observed in the circulation of patients with atherosclerosis and Type 2 diabetes relative to controls, consistent with the role of sialic acid as a biomarker for 
cardiometabolic diseases $[50,51]$. Our recent study showed that sialylation of total plasma proteins is increased in patients with diabetes, even before the onset of the disease [52].)

We found that removal of sialic acid residues from native HDL significantly diminished its efficacy in effluxing cellular cholesterol from THP-1 macrophages. The distinct role of sialylation for this key biological activity was highlighted by the experiments with the removal of other glycan moieties from HDL. Indeed, while the cleavage of galactose residues following that of sialic acids was without effect, complete removal of glycans by PNGase F reduced HDLmediated cholesterol efflux to an extent similar to that of the treatment with neuraminidase.

Cells possess several pathways to efflux cholesterol [53]. Cholesterol removal occurs according to cholesterol concentration gradient and is mediated by scavenger receptor class B type I (SR-BI) encoded by the SCARBI gene. Active pathways are mediated by ATP-binding cassette sub-family A member 1 (ABCA1) and ATP-binding cassette sub-family G member 1 (ABCG1) transporters, which are membrane lipid translocases [53]. We did not observe any differences in cholesterol efflux capacity of native and desialylated HDL from human THP-1 cells in which SCARBI or ABCAl expression were knocked-down. These data suggest that sialylation is required for optimal binding of HDL to SR-BI and ABCA1 [17].

Up to date, there is no evidence regarding the importance of sialylation for binding of HDL to macrophages. Since negatively charged acetylated HDL [54] and oxidized HDL [55] are recognized by scavenger receptors from rat hepatocytes and mouse peritoneal macrophages, it appears reasonable to suggest that of HDLs to scavenger receptors. The differential cholesterol efflux capacity of desialylated and native HDL can also be linked to ABCA1 but not to other, than ABCA1, transporters, such as ABCG1. It should be noted, however, that we achieved in our experiments approximately $80 \%$ silencing of mRNA production for SCARB1 and $A B C A 1$ relative to controls and cannot therefore ensure that the residual activity was not sufficient to maintain the efflux; these results should therefore be interpreted with caution. 
In addition to cellular cholesterol efflux, HDL desialylation may diminish cholesteryl esterification rate mediated by LCAT which is heavily N-glycosylated [24]. Consistent with these data, LCAT activity was markedly reduced following HDL desialylation in our present study. In addition, desialylation decreases HDL electronegativity [25]; as HDL charge exerts specific effects on lipolysis, decreasing the negative charge of HDL by desialylation might impact the association of lipases with HDL [56]. As N- and O-glycosylation of human apoA-I was recently reported $[57,58]$, desialylation might equally alter interactions of apoA-I with cellular proteins, including ABCA1. The question of apoA-I glycosylation remains controversial though as apoA-I-associated glycans were not detected in several studies employing LC/MS/MS $[26,28,29]$.

It is interesting that we observed a slight decrease in the mean HDL size following desialylation. Given that ABCA1 preferentially effluxes cholesterol to small relative to large HDL [59], such effect should have resulted in the elevated cholesterol efflux capacity of the desialylated particles, which was not the case, suggesting that other factors, including HDL charge, were more important for this functional alteration. We interpret these data to hypothesise that the $\mathrm{N}$-glycome of HDL proteins, including fetuin A, alpha-1-antitripsin, angiotensinogen [26, 28, 29], LCAT [24] and possibly apoA-I [57, 58], can be affected by neuroaminidaseinduced desialylation and that these modifications bear a potential to reduce electronegativity and LCAT activity of HDL to concomitantly contribute to the diminished capacity of HDL to efflux cellular cholesterol via ABCA1, counteracting potentially beneficial effects of the diminished HDL size.

LDL desialylation may equally have negative consequences in the metabolic context of atherosclerosis. Thus, LDL particles isolated from plasma of patients with coronary atherosclerosis are atherogenic, as they induce accumulation of cholesteryl esters in macrophages upon in vitro incubation, while LDL samples obtained from healthy donors are without effect [60-62]. Such atherogenic LDLs contained less sialic acid relative to their 
counterparts from healthy controls [10]. Consistent with these data and with an earlier report [17], we observed that desialylated LDL particles provoked cellular cholesteryl ester accumulation. In such desialylated LDL, a galactose residue preceding those of sialic acid in the carbohydrate chain becomes a terminal and externally exposed residue. In macrophages, desialylated LDL can be internalised via galactose-specific lectin receptors and/or the LDL receptor [23]. Interestingly, treatment with LPS up-regulates expression of galactose-specific lectins in macrophages that in turn increases cholesteryl ester accumulation after incubation of macrophages with desialylated LDL [18]. In addition, lipoprotein desialylation may elicit a faster cholesteryl ester transfer protein (CETP)-mediated cholesteryl ester (CE) transfer from HDL to LDL, thereby augmenting LDL cholesterol content [17].

It is well known that different techniques of in vitro LDL modification, including acetylation, methylation and oxidation, lead to the formation of electronegative LDL, which induce cellular cholesterol accumulation [63]. Importantly, electronegative LDL can form aggregates [64] that do not interact with scavenger receptors, including CD36 and SR-A, nor with the LDL receptor and associate with macrophages in a high- capacity, receptor-independent manner [65]. Unlike desialylated LDL, oxidized LDL are known to interact with cells via CD36, SR-AI, SR-AII and LOX-1 scavenger receptors [66]. Pathologically, desialylation of LDL might represent an early atherogenic modification in vivo that does not lead to LDL interaction with scavenger receptors but may still cause a domino effect of further alterations, amplifying the atherogenicity of the particles [9, 67]. At the end, LDL which underwent such multiple modifications enters the cells through scavenger receptors, signifying the climax of a perfect storm of atherogenic modifications.

Our study is not free of limitations which need to be acknowledged. First, the sample size was small, indicating that this was a pilot study whose findings need to be confirmed in larger populations. Second, as we only recruited male subjects, our results cannot be generalised to a general population and require confirmation in women. 
In conclusion, our study demonstrates that the $\mathrm{N}$-glycomes of human plasma HDL and LDL reveal a high level of diversity, which directly impacts their biological properties. Our data indicate that sialylation of human plasma HDL and LDL represents an important determinant of their biological function. We further propose that analysis of $\mathrm{N}$-glycomic profiles of lipoproteins bears a potential to be used in clinical practice to detect the presence of desialylated LDL and HDL, which can serve as biomarkers of CVD risk. 


\section{Acknowledgements and sources of funding}

These studies were supported by National Institute for Health and Medical Research (INSERM) and ANR (CARINA project) in Paris, France, by Russian Science Foundation (Grant \# 14-1500112), by the European Union Seventh Framework H2020 grants SYSCID (contract \#733100), GlySign (contract \#722095), and IMForFuture (contract \#721815), and by the European Structural and Investment Funds IRI grant (contract \#KK.01.2.1.01.0003) and Croatian National Centre of Research Excellence in Personalized Healthcare grant (contract \#KK.01.1.1.01.0010). 


\section{Figure Legends}

Fig. 1. Representative chromatogram of 2-AB labeled N-linked glycans released from native HDL (A) and LDL (B) and separated by HILIC-UHPLC-FLD. The integration areas, together with major structures present in each chromatographic peak are given.

\section{Fig. 2. Representative HILIC-UHPLC-FLD chromatograms of 2-AB labeled N-linked} glycans released from native and neuraminidase-treated human HDL (A) and LDL (B). Chromatographic peaks containing N-glycans affected by neuraminidase treatment are shaded in grey.

Fig. 3. Relative abundance of individual glycan peaks in native and neuraminidase-treated human HDL (A) and LDL (B). Mean values \pm SDs obtained in six samples isolated from six donors are shown; $* \mathrm{p}<0.05$ for differences between corresponding glycomic moieties from control vs. desialylated samples. The numbers near the bars represent the fold difference of mean values of two groups in peaks where the difference of means is significant.

Fig. 4. Influence of the treatment with neuraminidase and other enzymes on biological properties of human HDL and LDL. Cellular cholesterol efflux capacity of native and neuraminidase-treated human HDL in macrophagic THP-1 cells (A), cellular cholesterol efflux capacity of native, neuraminidase-, neuraminidase $+\beta$ Galactosidase-, PNGaseF-treated human HDL in macrophagic THP-1 cells (B), and accumulation in THP-1 cells of cholesteryl ester derived from native and neuraminidase-treated human LDL (C) are shown. Mean values \pm SDs obtained in six samples isolated from six donors were as follows: (A) $8.63 \pm 1.45$ vs. $7.21 \pm 1.00$ $\%$ for native and neuraminidase-treated HDL, respectively ( $\mathrm{p}<0.05$ for the difference); (B) 7.89 $\pm 3.16 \%$ for control (baseline efflux), $6.99 \pm 2.62$ for neuraminidase-treated, $6.63 \pm 2.18$ for neuraminidase and $\beta$-Galactosidase-treated, and $6.26 \pm 1.76$ for PNGaseF-treated HDL $(\mathrm{p}<0.05$ for control vs neuraminidase, control vs neuraminidase+ $\beta$ Galactosidase, control vs PNGaseF); 
(C) $0.49 \pm 0.25 \%$ vs. $0.18 \pm 0.09 \%$ for native and neuraminidase-treated LDL, respectively $(\mathrm{p}<0.05$ for the difference).

Fig. 5. Relationships between the N-glycome and biological properties of HDL and LDL. Correlations between cellular cholesterol efflux capacity of HDL and area of the peak 13 (A) and between cellular cholesteryl ester accumulation induced by LDL and area of the peak 9 (B) are shown. 
Table 1. Composition of the HDL N-glycome. HDL N-glycome was separated into 22 chromatographic peaks by HILIC-UHPLC-FLD and masses of individual glycan structures were detected by MALDI-TOF MS.

\section{Registered}

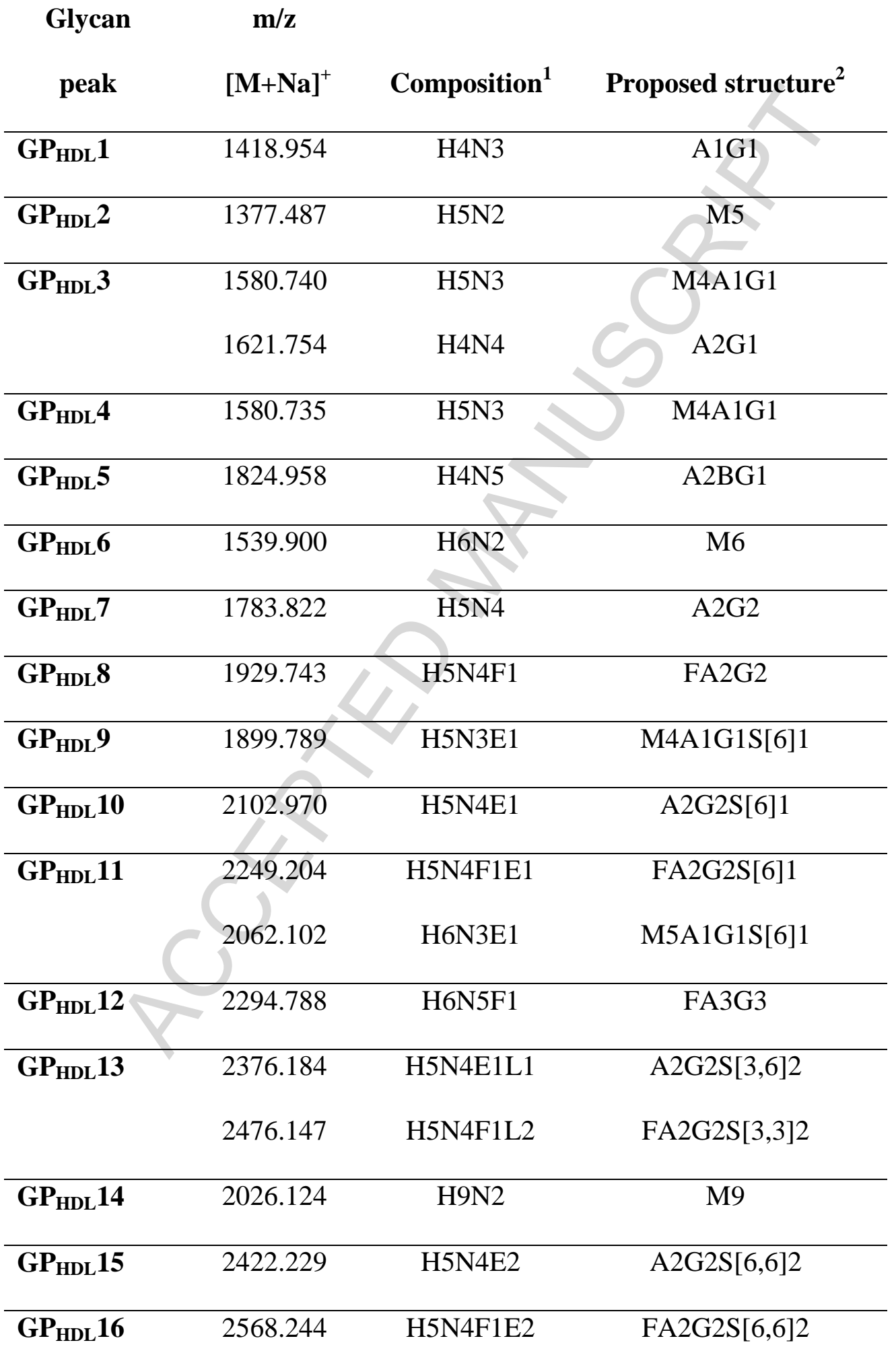




\begin{tabular}{|c|c|c|c|}
\hline \multirow[b]{2}{*}{$\mathbf{G P}_{\mathrm{HDL}} 17$} & & \multirow[b]{2}{*}{ H6N5E1L1 } & \\
\hline & 2741.402 & & A3G3S $[3,6] 2$ \\
\hline GP $_{\text {HDL }} 18$ & 2841.466 & H6N5F1L2 & FA3G3S[3,3]2 \\
\hline GP $_{\text {HDL }} 19$ & 2787.273 & H6N5E2 & A3G3S[6,6]2 \\
\hline $\mathbf{G P}_{\mathrm{HDL}} 20$ & 2933.446 & H7N6F1L1 & FA4G4S[3]1 \\
\hline $\mathbf{G P}_{\mathrm{HDL}} 21$ & 3060.590 & H6N5E1L2 & A3G3S $[3,6,6] 3$ \\
\hline $\mathbf{G P}_{\mathrm{HDL}} 22$ & 3206.680 & H6N5F1E2L1 & A3F1G3S $[3,6,6] 3$ \\
\hline
\end{tabular}

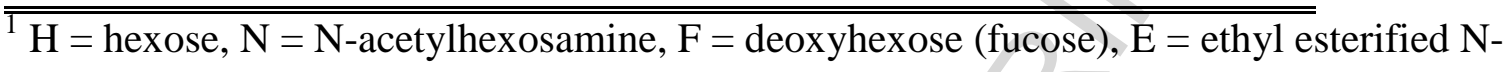
acetylneuraminic acid ( $\alpha$ 2,6-linked), $\mathrm{L}=$ lactonized $\mathrm{N}$-acetylneuraminic acid ( $\alpha 2,3$-linked). ${ }^{2}$ Abbreviations used: all N-glycans possess a core sugar sequence consisting of two Nacetylglucosamines (GlcNAc) and three mannose residues; F at the start of abbreviation indicates a core fucose $\alpha 1-6$ linked to the inner GlcNAc; Mx, number (x) of mannoses on core GlcNAc; Ax, number (x) of antennas (GlcNAc) on trimannosyl core; Fx, number (x) of fucose linked $\alpha 1-3$ to antenna GlcNAc; Gx, number (x) of $\beta 1-4$ linked galactoses on antenna; Sx, number (x) of sialic acids linked to galactose; LacdiNAc(x), number (x) of lacdiNAc (GalNAc $\beta 1-4 G l c N A c)$ extensions. 
Table 2. Composition of the LDL N-glycome. LDL N-glycome was separated into 18 chromatographic peaks by HILIC-UHPLC-FLD and masses of individual glycan structures were detected by MALDI-TOF MS.

\section{Registered}

\begin{tabular}{|c|c|c|c|}
\hline \multirow{2}{*}{$\begin{array}{c}\text { Glycan } \\
\text { peak }\end{array}$} & \multicolumn{2}{|l|}{$\mathbf{m} / \mathbf{z}$} & \multirow[b]{2}{*}{ Proposed structure $^{2}$} \\
\hline & {$[\mathbf{M}+\mathbf{N a}]^{+}$} & Composition $^{1}$ & \\
\hline $\mathbf{G P}_{\text {LDL }} \mathbf{1}$ & 1418.526 & H4N3 & A1G1 \\
\hline $\mathbf{G P}_{\mathrm{LDL}} 2$ & 1377.596 & H5N2 & M5 \\
\hline $\mathbf{G P}_{\mathrm{LDL}} 3$ & 1621.655 & H4N4 & $\mathrm{A} 2 \mathrm{G} 1$ \\
\hline $\mathbf{G P}_{\mathrm{LDL}} \mathbf{4}$ & 1580.656 & H5N3 & M4A1G1 \\
\hline $\mathbf{G P}_{\text {LDL }} 5$ & 1539.65 & H6N2 & M6 \\
\hline $\mathbf{G P}_{\text {LDL }} 6$ & 1783.701 & H5N4 & $\mathrm{A} 2 \mathrm{G} 2$ \\
\hline $\mathbf{G P}_{\text {LDL }} 7$ & 1929.885 & H5N4F1 & FA2G2 \\
\hline \multirow[t]{2}{*}{$\mathbf{G P}_{\text {LDL }} 8$} & 1701.661 & H7N2 & M7 \\
\hline & 2081.946 & H3N5F1L1 & FA1LacdiNAcS[3]1 \\
\hline \multirow[t]{3}{*}{$\mathbf{G P}_{\text {LDL }} 9$} & 1701.578 & H7N2 & M7 \\
\hline & 2056.708 & H5N4L1 & $\mathrm{A} 2 \mathrm{G} 2 \mathrm{~S}[3] 1$ \\
\hline & 1899.659 & H5N3E1 & M4A1G1S[6]1 \\
\hline \multirow[t]{2}{*}{$\mathbf{G P}_{\mathrm{LDL}} \mathbf{1 0}$} & 2102.79 & H5N4E1 & A2G2S[6]1 \\
\hline & 2244.025 & H4N5F1L1 & FA2BG1S[3]1 \\
\hline GP $_{\text {LDL }} 11$ & 1863.646 & H8N2 & M8 \\
\hline \multirow[t]{2}{*}{$\mathbf{G P}_{\mathrm{LDL}} 12$} & 1863.624 & H8N2 & M8 \\
\hline & 2061.715 & H6N3E1 & M5A1G1S[6]1 \\
\hline \multirow[t]{2}{*}{$\mathbf{G P}_{\text {LDL }} 13$} & 2375.82 & H5N4E1L1 & A2G2S $[3,6] 2$ \\
\hline & 2517.012 & H4N5F1L2 & FA1G1LacdiNAcS[3,3]2 \\
\hline
\end{tabular}




\begin{tabular}{lccc} 
GP $_{\text {LDL } 14}$ & 2025.825 & H9N2 & M9 \\
\hline GP $_{\text {LDL } 15}$ & 2421.876 & H5N4E2 & A2G2S[6,6]2 \\
& 2563.118 & H4N5F1E1L1 & FA1G1LacdiNAcS $[3,6] 2$ \\
\hline GP $_{\text {LDL } 16}$ & 2740.958 & H6N5E1L1 & A3G3S[3,6]2 \\
\hline GP $_{\text {LDL } 17}$ & 2786.981 & H6N5E2 & A3G3S[6,6]2 \\
\hline GP $_{\text {LDL } 18}$ & 3060.109 & H6N5E1L2 & A3G3S[3,3,6]3 \\
& 3201.328 & H5N6E1L2 & FA2G2LacdiNAcS $[3,3,6] 2$
\end{tabular}

${ }^{\mathrm{T}}$ Composition and structures as in Table 1. 
Table 3. Correlation coefficients between $\mathbf{N}$-glycomic composition and cellular cholesterol efflux capacity of HDL

Peak number Control samples Neuraminidase-treated samples

$$
(\mathrm{n}=6) \quad(\mathrm{n}=6)
$$

\begin{tabular}{|c|c|c|}
\hline $\mathbf{G P}_{\mathrm{HDL}} \mathbf{1}$ & 0.29 & -0.1 \\
\hline $\mathbf{G P}_{\mathrm{HDL}} 2$ & -0.72 & -0.88 \\
\hline$G P_{H D L} 3$ & -0.69 & -0.55 \\
\hline $\mathbf{G P}_{\mathrm{HDL}}$ & 0.25 & -0.15 \\
\hline $\mathbf{G P}_{\mathrm{HDL}} 5$ & 0.06 & 0.71 \\
\hline $\mathbf{G P}_{\mathrm{HDL}} 6$ & -0.69 & -0.85 \\
\hline $\mathbf{G P}_{\mathrm{HDL}} 7$ & -0.35 & -0.66 \\
\hline $\mathbf{G P}_{\mathrm{HDL}} 8$ & 0.67 & 0.84 \\
\hline $\mathbf{G P}_{\mathrm{HDL}} 9$ & 0.55 & 1.2 \\
\hline $\mathbf{G P}_{\mathrm{HDL}} 10$ & & -0.55 \\
\hline $\mathbf{G P}_{\mathrm{HDL}} 11$ & 0.83 & 0.65 \\
\hline $\mathbf{G P}_{\mathrm{HDL}} 12$ & 0.15 & 0.78 \\
\hline $\mathbf{G P}_{\mathrm{HDL}} 13$ & 0.84 & 0.20 \\
\hline $\mathbf{G P}_{\mathrm{HDL}} 14$ & -0.92 & -0.89 \\
\hline $\mathbf{G P}_{\mathrm{HDL}} 15$ & 0.00 & 0.00 \\
\hline $\mathbf{G P}_{\mathrm{HDL}} 16$ & 0.20 & 0.08 \\
\hline
\end{tabular}




\begin{tabular}{lll}
$\mathbf{G P}_{\mathbf{H D L}} \mathbf{1 7}$ & 0.11 & 0.10 \\
$\mathbf{G P}_{\mathbf{H D L}} \mathbf{1 8}$ & 0.59 & 0.57 \\
$\mathbf{G P}_{\mathbf{H D L}} \mathbf{1 9}$ & -0.27 & 0.30 \\
$\mathbf{G P}_{\mathbf{H D L}} \mathbf{2 0}$ & 0.23 & 0.40 \\
$\mathbf{G P}_{\mathbf{H D L}} \mathbf{2 1}$ & 0.05 & 0.43 \\
$\mathbf{G P}_{\mathbf{H D L}} \mathbf{2 2}$ & -0.15 & $\mathbf{0 . 8 2}$ \\
\hline Significant correlations are shown in bold $\mathrm{p}<0.05$
\end{tabular}

Significant correlations are shown in bold; $\mathrm{p}<0.05$. 
Table 4. Correlation coefficients between glycomic composition and capacity of LDL to induce cellular cholesteryl esters accumulation

\begin{tabular}{|c|c|c|}
\hline Peak number & $\begin{array}{l}\text { Control samples } \\
(\mathrm{n}=6)\end{array}$ & $\begin{array}{l}\text { Neuraminidase-treated } \\
\text { samples }(n=6)\end{array}$ \\
\hline $\mathbf{G P}_{\text {LDL }} \mathbf{1}$ & -0.71 & -0.44 \\
\hline $\mathbf{G P}_{\mathrm{LDL}} 2$ & -0.08 & 0.02 \\
\hline $\mathbf{G P}_{\mathrm{LDL}} \mathbf{3}$ & -0.72 & -0.58 \\
\hline $\mathbf{G P}_{\mathrm{LDL}} 4$ & -0.79 & -0.54 \\
\hline$G_{\text {LDL }} 5$ & -0.23 & 0.02 \\
\hline$G P_{L D L} 6$ & -0.58 & -0.22 \\
\hline $\mathbf{G P}_{\mathrm{LDL}} 7$ & -0.45 & -0.31 \\
\hline $\mathbf{G P}_{\mathrm{LDL}} 8$ & -0.66 & -0.80 \\
\hline $\mathbf{G P}_{\text {LDL }} 9$ & -0.41 & \\
\hline $\mathbf{G P}_{\mathrm{LDL}} \mathbf{1 0}$ & -0.53 & 0.30 \\
\hline $\mathbf{G P}_{\mathrm{LDL}} 11$ & -0.78 & -0.69 \\
\hline $\mathbf{G P}_{\mathrm{LDL}} 12$ & -0.28 & -0.44 \\
\hline $\mathbf{G P}_{\mathrm{LDL}} 13$ & 0.59 & 0.66 \\
\hline $\mathbf{G P}_{\mathrm{LDL}} 14$ & -0.17 & 0.14 \\
\hline $\mathbf{G P}_{\mathrm{LDL}} \mathbf{1 5}$ & 0.80 & 0.30 \\
\hline $\mathbf{G P}_{\mathrm{LDL}} 16$ & 0.69 & 0.88 \\
\hline
\end{tabular}




\section{$\begin{array}{lll}\text { GP }_{\text {LDL }} 17 & 0.75 & 0.28\end{array}$}

$\begin{array}{lll}\mathbf{G P}_{\text {LDL }} \mathbf{1 8} & 0.66 & 0.47\end{array}$

Significant correlations are shown in bold; $\mathrm{p}<0.05$. 


\section{References}

1. $\quad$ Lusis, A.J., Atherosclerosis. Nature, 2000. 407(6801): p. 233-41.

2. Glomset, J.A., The plasma lecithins:cholesterol acyltransferase reaction. J Lipid Res, 1968. 9(2): p. 155-67.

3. Wang, H.H., et al., Cholesterol and Lipoprotein Metabolism and Atherosclerosis: Recent Advances In reverse Cholesterol Transport. Ann Hepatol, 2017. 16(0): p. 21-36.

4. Scanu, A., Forms of human serum high density lipoprotein protein. J Lipid Res, 1966. 7(2): p. 295-306.

5. Vauhkonen, M., et al., High-mannose structure of apolipoprotein-B from low-density lipoproteins of human plasma. Eur J Biochem, 1985. 152(1): p. 43-50.

6. Tertov, V.V., et al., Carbohydrate composition of protein and lipid components in sialic acid-rich and -poor low density lipoproteins from subjects with and without coronary artery disease. J Lipid Res, 1993. 34(3): p. 365-75.

7. Swaminathan, N. and F. Aladjem, The monosaccharide composition and sequence of the carbohydrate moiety of human serum low density lipoproteins. Biochemistry, 1976. 15(7): p. 1516-22.

8. Huang, J., et al., Glycomic analysis of high density lipoprotein shows a highly sialylated particle. J Proteome Res, 2014. 13(2): p. 681-91.

9. $\quad$ Orekhov, A.N., et al., Modified Low Density Lipoprotein and Lipoprotein-Containing Circulating Immune Complexes as Diagnostic and Prognostic Biomarkers of Atherosclerosis and Type 1 Diabetes Macrovascular Disease. International Journal of Molecular Sciences, 2014. 15(7): p. 12807-12841.

10. Orekhov, A.N., et al., Modification of low density lipoprotein by desialylation causes lipid accumulation in cultured cells: discovery of desialylated lipoprotein with altered cellular metabolism in the blood of atherosclerotic patients. Biochem Biophys Res Commun, 1989. 162(1): p. 206-11.

11. Sobenin, I.A., et al., Modified low density lipoprotein from diabetic patients causes cholesterol accumulation in human intimal aortic cells. Atherosclerosis, 1993. 100(1): p. 41-54.

12. Tertov, V.V., et al., Isolation of atherogenic modified (desialylated) low density lipoprotein from blood of atherosclerotic patients: separation from native lipoprotein by affinity chromatography. Biochem Biophys Res Commun, 1990. 167(3): p. 1122-7.

13. Orekhov, A.N., et al., Sialic acid content of human low density lipoproteins affects their interaction with cell receptors and intracellular lipid accumulation. J Lipid Res, 1992. 33(6): p. 805-17.

14. Tertov, V.V., et al., Characteristics of low density lipoprotein isolated from circulating immune complexes. Atherosclerosis, 1996. 122(2): p. 191-9.

15. Orekhov, A.N., V.V. Tertov, and D.N. Mukhin, Desialylated low density lipoprotein-naturally occurring modified lipoprotein with atherogenic potency. Atherosclerosis, 1991. 86(2-3): p. 153-61.

16. Tertov, V.V., et al., Lipoprotein aggregation as an essential condition of intracellular lipid accumulation caused by modified low density lipoproteins. Biochem Biophys Res Commun, 1989. 163(1): p. 489-94.

17. Harada, L.M., et al., Lipoprotein desialylation simultaneously enhances the cell cholesterol uptake and impairs the reverse cholesterol transport system: in vitro evidences utilizing neuraminidase-treated lipoproteins and mouse peritoneal macrophages. Atherosclerosis, 1998. 139(1): p. 65-75.

18. Bartlett, A.L., et al., Role of the macrophage galactose lectin in the uptake of desialylated $L D L$. Atherosclerosis, 2000. 153(1): p. 219-30. 
19. Hunt, J.V., et al., Glucose oxidation and low-density lipoprotein-induced macrophage ceroid accumulation: possible implications for diabetic atherosclerosis. Biochemical Journal, 1994. 300(Pt 1): p. 243-249.

20. Brown, B.E., et al., Glycation of low-density lipoprotein results in the time-dependent accumulation of cholesteryl esters and apolipoprotein B-100 protein in primary human monocyte-derived macrophages. Febs j, 2007. 274(6): p. 1530-41.

21. Chisolm, G.M. and D. Steinberg, The oxidative modification hypothesis of atherogenesis: an overview. Free Radic Biol Med, 2000. 28(12): p. 1815-26.

22. Orekhov, A.N., V.V. Tertov, and D.N. Mukhin, Desialylated low density lipoprotein naturally occurring modified lipoprotein with atherogenic potency. Atherosclerosis, 1991. 86(2): p. 153-161.

23. Grewal, T., et al., Desialylated LDL uptake in human and mouse macrophages can be mediated by a lectin receptor. Atherosclerosis, 1996. 121(1): p. 151-63.

24. Dobiasova, M., Lecithin: cholesterol acyltransferase and the regulation of endogenous cholesterol transport. Adv Lipid Res, 1983. 20: p. 107-94.

25. Marmillot, P., et al., Desialylation of human apolipoprotein E decreases its binding to human high-density lipoprotein and its ability to deliver esterified cholesterol to the liver. Metabolism, 1999. 48(9): p. 1184-92.

26. Krishnan, S., et al., Combined High-Density Lipoprotein Proteomic and Glycomic Profiles in Patients at Risk for Coronary Artery Disease. J Proteome Res, 2015. 14(12): p. 5109-18.

27. Savinova, O.V., et al., Reduced apolipoprotein glycosylation in patients with the metabolic syndrome. PLoS One, 2014. 9(8): p. e104833.

28. Krishnan, S., et al., HDL Glycoprotein Composition and Site-Specific Glycosylation Differentiates Between Clinical Groups and Affects IL-6 Secretion in Lipopolysaccharide-Stimulated Monocytes. Sci Rep, 2017. 7: p. 43728.

29. Kailemia, M.J., et al., Targeted measurements of $O$ - and $\mathrm{N}$-glycopeptides show that proteins in HDL particles are enriched with specific glycosylation compared to plasma. $\mathrm{J}$ Proteome Res, 2017.

30. Rumsey, S.C., et al., Cryopreservation with sucrose maintains normal physical and biological properties of human plasma low density lipoproteins. J Lipid Res, 1992. 33(10): p. 1551-1561.

31. Chapman, M.J., et al., A density gradient ultracentrifugal procedure for the isolation of the major lipoprotein classes from human serum. J Lipid Res, 1981. 22(2): p. 339-58.

32. Guerin, M., et al., Fenofibrate reduces plasma cholesteryl ester transfer from HDL to $V L D L$ and normalizes the atherogenic, dense LDL profile in combined hyperlipidemia. Arterioscler Thromb Vasc Biol, 1996. 16(6): p. 763-72.

33. Guerin, M., et al., Dose-dependent action of atorvastatin in type IIB hyperlipidemia: preferential and progressive reduction of atherogenic apoB-containing lipoprotein subclasses (VLDL-2, IDL, small dense LDL) and stimulation of cellular cholesterol efflux. Atherosclerosis, 2002. 163(2): p. 287-96.

34. Kontush, A., S. Chantepie, and M.J. Chapman, Small, dense HDL particles exert potent protection of atherogenic LDL against oxidative stress. Arterioscler Thromb Vasc Biol, 2003. 23(10): p. 1881-1888.

35. Camont, L., et al., Small, dense high-density lipoprotein-3 particles are enriched in negatively charged phospholipids: relevance to cellular cholesterol efflux, antioxidative, antithrombotic, anti-inflammatory, and antiapoptotic functionalities. Arterioscler Thromb Vasc Biol, 2013. 33(12): p. 2715-23.

36. Kontush, A., et al., Antioxidative activity of HDL particle subspecies is impaired in hyperalphalipoproteinemia: relevance of enzymatic and physicochemical properties. Arterioscler Thromb Vasc Biol, 2004. 24(3): p. 526-33. 
37. Akmacic, I.T., et al., High-throughput glycomics: optimization of sample preparation. Biochemistry (Mosc), 2015. 80(7): p. 934-42.

38. Reiding, K.R., et al., High-throughput profiling of protein N-glycosylation by MALDITOF-MS employing linkage-specific sialic acid esterification. Anal Chem, 2014. 86(12): p. 5784-93.

39. Larrede, S., et al., Stimulation of cholesterol efflux by LXR agonists in cholesterol-loaded human macrophages is ABCA1-dependent but ABCG1-independent. Arterioscler Thromb Vasc Biol, 2009. 29(11): p. 1930-6.

40. Fournier, N., et al., Analysis of the relationship between triglyceridemia and HDLphospholipid concentrations: consequences on the efflux capacity of serum in the Fu5AH system. Atherosclerosis, 2001. 157(2): p. 315-23.

41. Bellanger, N., et al., Atheroprotective reverse cholesterol transport pathway is defective in familial hypercholesterolemia. Arterioscler Thromb Vasc Biol, 2011. 31(7): p. 167581.

42. Lindbohm, N., H. Gylling, and T.A. Miettinen, Sialic acid content of low density lipoprotein and its relation to lipid concentrations and metabolism of low density lipoprotein and cholesterol. J Lipid Res, 2000. 41(7): p. 1110-7.

43. Ruhaak, L.R., et al., Hydrophilic interaction chromatography-based high-throughput sample preparation method for $N$-glycan analysis from total human plasma glycoproteins. Anal Chem, 2008. 80(15): p. 6119-26.

44. Vaisar, T., Proteomics investigations of HDL: challenges and promise. Curr Vasc Pharmacol, 2012. 10(4): p. 410-21.

45. Vauhkonen, M., et al., High-mannose structure of apolipoprotein-B from low-density lipoproteins of human plasma. European Journal of Biochemistry, 1985. 152(1): p. 4350.

46. Varki, A., Sialic acids in human health and disease. Trends Mol Med, 2008. 14(8): p. 351-60.

47. Schauer, R., Sialic acids as regulators of molecular and cellular interactions. Curr Opin Struct Biol, 2009. 19(5): p. 507-14.

48. Lehmann, F., E. Tiralongo, and J. Tiralongo, Sialic acid-specific lectins: occurrence, specificity and function. Cell Mol Life Sci, 2006. 63(12): p. 1331-54.

49. Weigel, P.H. and J.H. Yik, Glycans as endocytosis signals: the cases of the asialoglycoprotein and hyaluronan/chondroitin sulfate receptors. Biochim Biophys Acta, 2002. 1572(2-3): p. 341-63.

50. Lindberg, G., et al., Serum sialic acid concentration and cardiovascular mortality. Bmj, 1991. 302(6769): p. 143-6.

51. Yokoyama, H., et al., Serum sialic acid concentration is elevated in IDDM especially in early diabetic nephropathy. J Intern Med, 1995. 237(5): p. 519-23.

52. Keser, T., et al., Increased plasma $N$-glycome complexity is associated with higher risk of type 2 diabetes. Diabetologia, 2017. 60(12): p. 2352-2360.

53. Phillips, M.C., Molecular Mechanisms of Cellular Cholesterol Efflux. J Biol Chem, 2014. 289(35): p. 24020-9.

54. Murakami, M., et al., Distinction in the mode of receptor-mediated endocytosis between high density lipoprotein and acetylated high density lipoprotein: evidence for high density lipoprotein receptor-mediated cholesterol transfer. J Biochem, 1987. 101(3): p. 729-41.

55. La Ville, A.E., et al., In vitro oxidised HDL is recognised by the scavenger receptor of macrophages: implications for its protective role in vivo. Atherosclerosis. 105(2): p. 179189.

56. Boucher, J.G., T. Nguyen, and D.L. Sparks, Lipoprotein electrostatic properties regulate hepatic lipase association and activity. Biochem Cell Biol, 2007. 85(6): p. 696-708. 
57. Cubedo, J., T. Padro, and L. Badimon, Glycoproteome of human apolipoprotein A-I: Nand $O$-glycosylated forms are increased in patients with acute myocardial infarction. Transl Res, 2014. 164(3): p. 209-22.

58. Majek, P., et al., $N$-Glycosylation of apolipoprotein Al in cardiovascular diseases. Transl Res, 2015. 165(2): p. 360-2.

59. Du, X.M., et al., HDL particle size is a critical determinant of ABCA1-mediated macrophage cellular cholesterol export. Circ Res, 2015. 116(7): p. 1133-42.

60. Orekhov, A.N., et al., Blood serum atherogenicity associated with coronary atherosclerosis. Evidence for nonlipid factor providing atherogenicity of low-density lipoproteins and an approach to its elimination. Circ Res, 1988. 62(3): p. 421-9.

61. Tertov, V.V., et al., Low-density lipoproteins isolated from the blood of patients with coronary heart disease induce the accumulation of lipids in human aortic cells. Exp Mol Pathol, 1989. 50(3): p. 337-47.

62. Chazov, E.I., et al., Atherogenicity of blood serum from patients with coronary heart disease. Lancet, 1986. 2(8507): p. 595-8.

63. Liu, Y. and D. Atkinson, Enhancing the contrast of ApoB to locate the surface components in the 3D density map of human LDL. J Mol Biol, 2011. 405(1): p. 274-83.

64. Sanchez-Quesada, J.L., S. Villegas, and J. Ordonez-Llanos, Electronegative low-density lipoprotein. A link between apolipoprotein B misfolding, lipoprotein aggregation and proteoglycan binding. Curr Opin Lipidol, 2012. 23(5): p. 479-86.

65. Boyanovsky, B.B., D.R. van der Westhuyzen, and N.R. Webb, Group V secretory phospholipase A2-modified low density lipoprotein promotes foam cell formation by a $S R-A-$ and CD36-independent process that involves cellular proteoglycans. J Biol Chem, 2005. 280(38): p. 32746-52.

66. Moore, K.J. and M.W. Freeman, Scavenger receptors in atherosclerosis: beyond lipid uptake. Arterioscler Thromb Vasc Biol, 2006. 26(8): p. 1702-11.

67. Tertov, V.V., et al., Antioxidant content in low density lipoprotein and lipoprotein oxidation in vivo and in vitro. Free Radic Res, 1998. 29(2): p. 165-73. 
No conflict of interest to declare

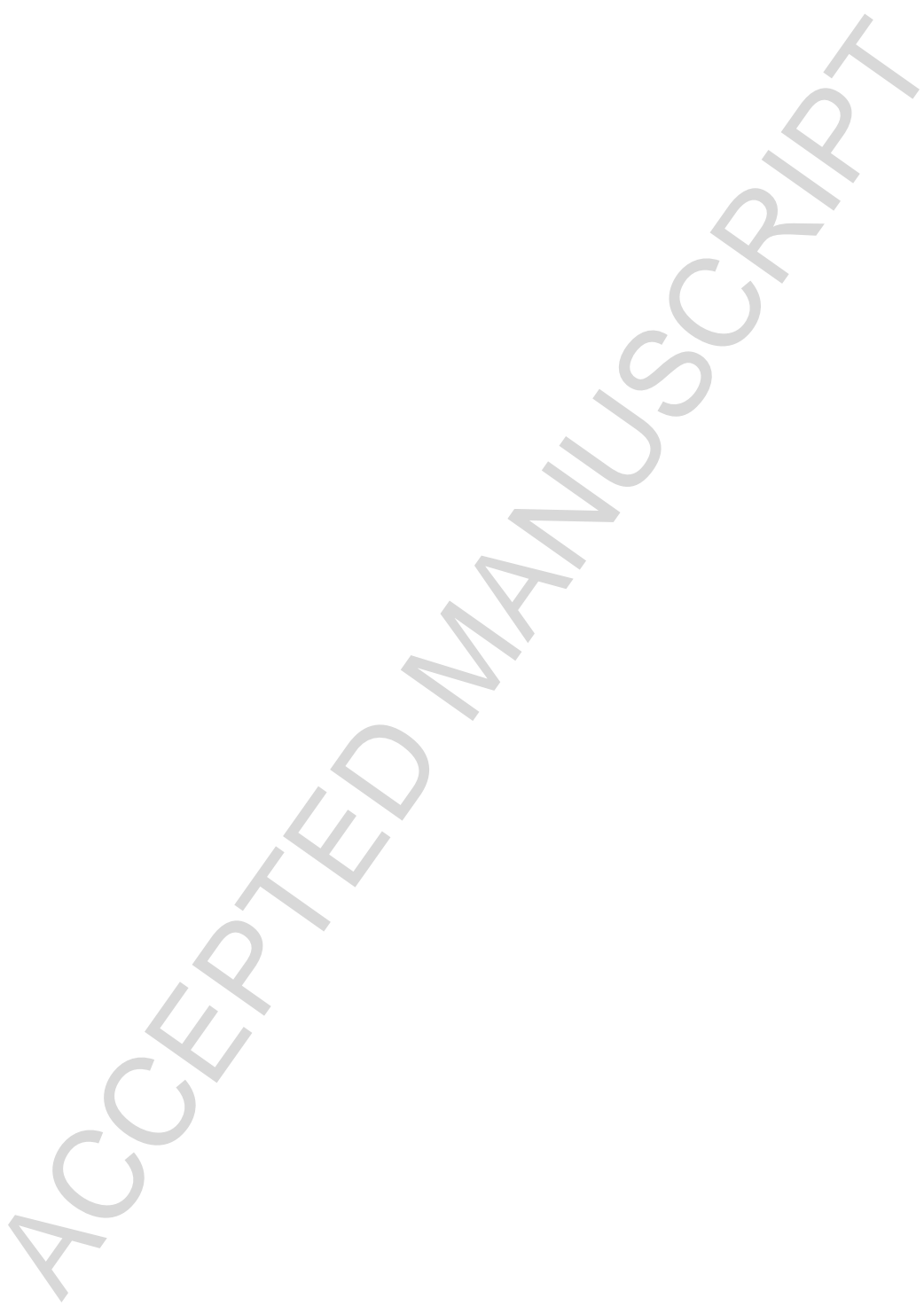




\section{Highlights}

HILIC-UHPLC-FLD analysis of HDL N-glycans released by PNGase F resulted in 22 peaks

HILIC-UHPLC-FLD analysis of LDL N-glycans released by PNGase F resulted in 18 peaks

The majority of N-glycans of LDL were sialylated with one or two sialic acid residues

The majority of N-glycans of HDL were sialylated with one or two sialic acid residues

Biantennary N-glycan with one sialic acid is the most abundant glycans in HDL and LDL

Neuraminidase treatment altered relative abundances of several N-glycan structures

Native HDL removes cholesterol from THP-1 cells better than desialylated HDL.

Desialylated LDL increases cellular accumulation of cholesteryl esters in THP1 cells. 
A
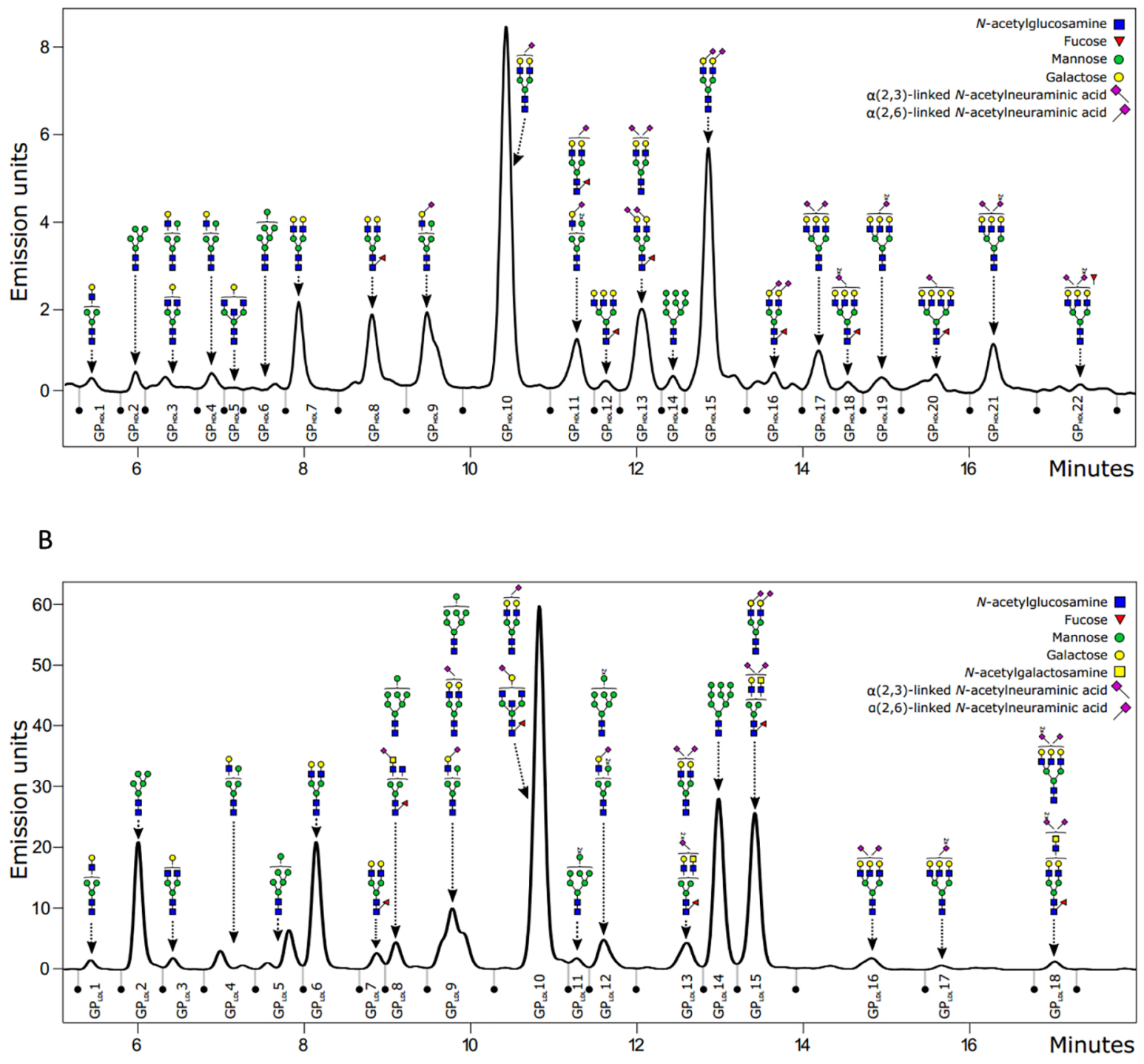

Figure 1 
A

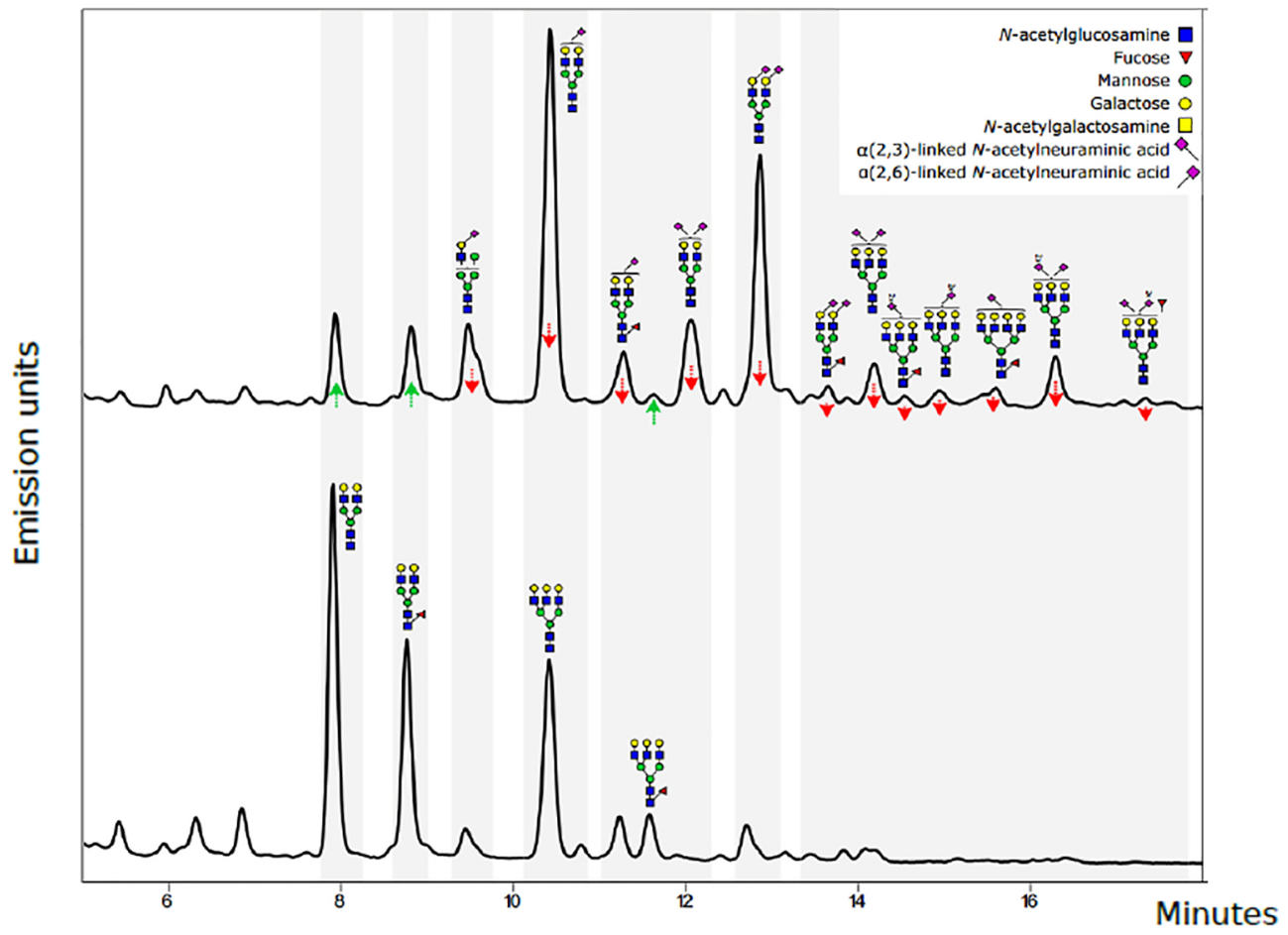

B

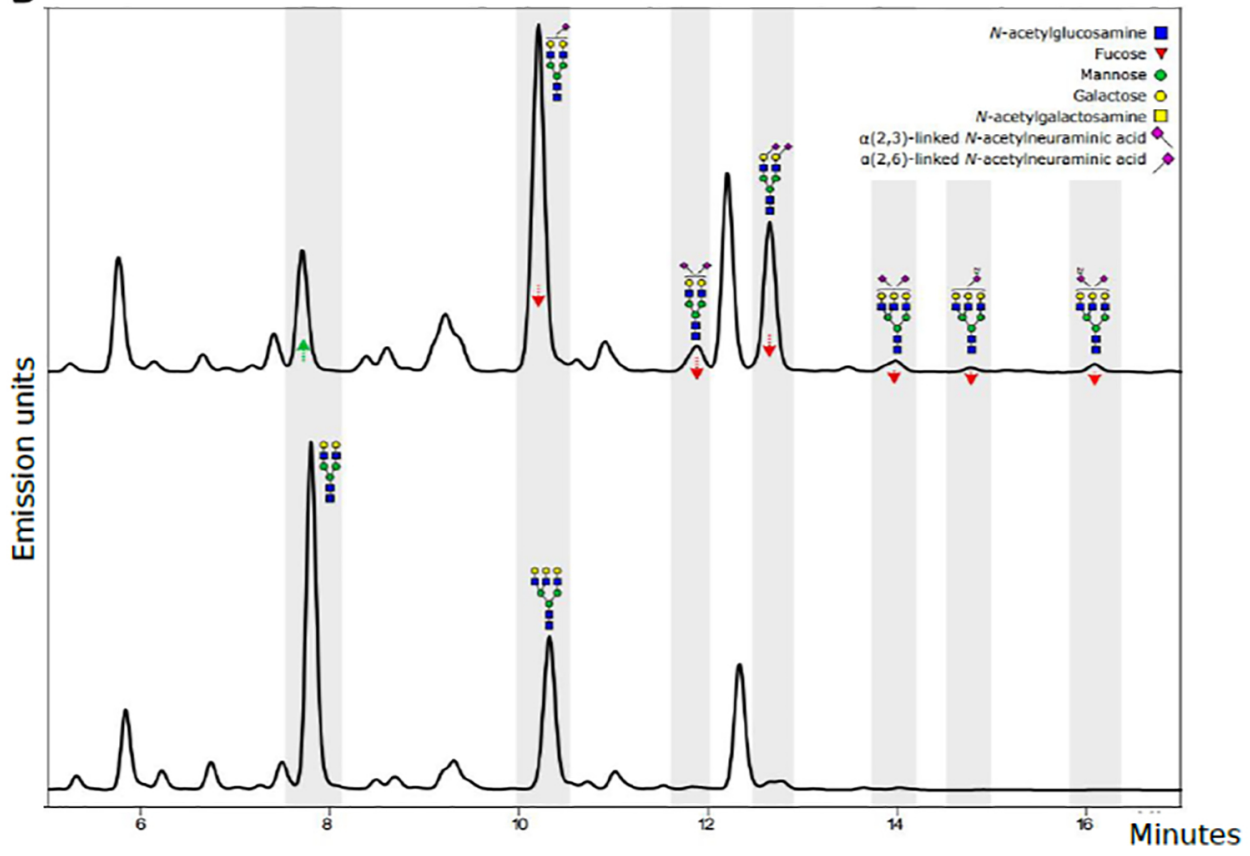

Figure 2 


\section{A}

HDL

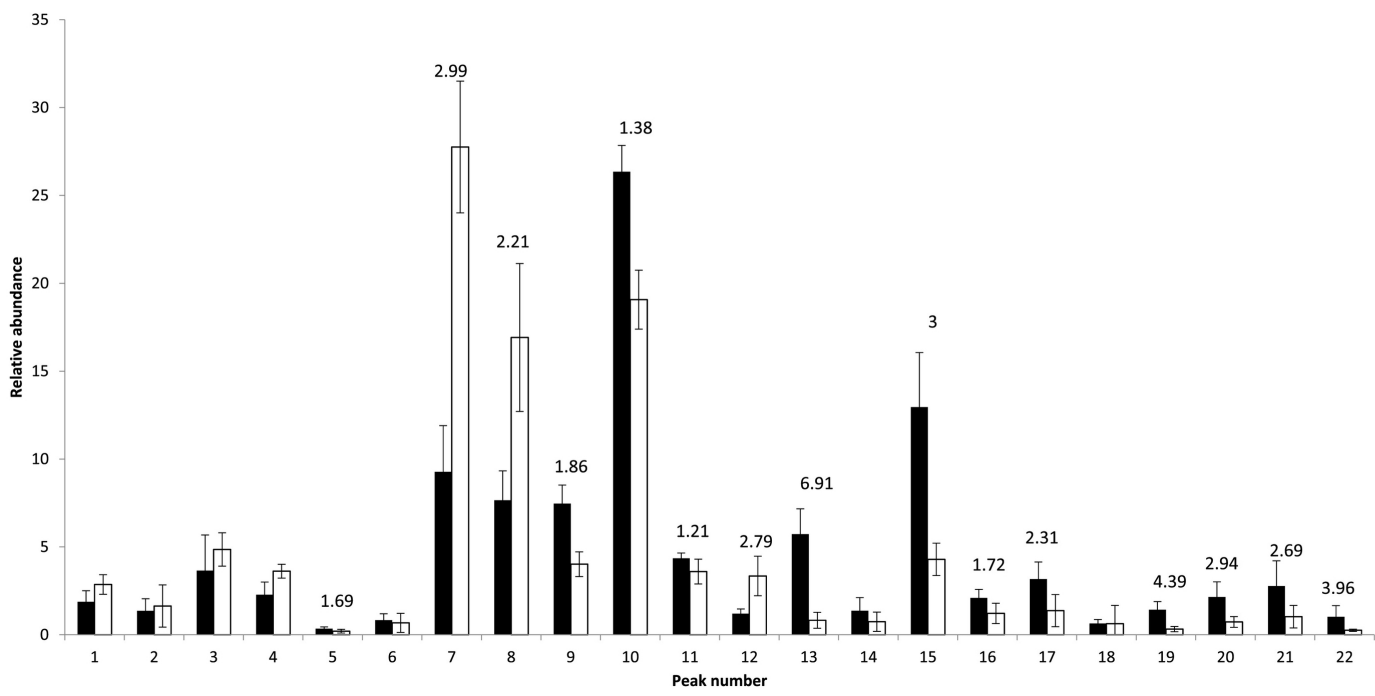

- Control

$\square$ Neuraminidase-treated

B

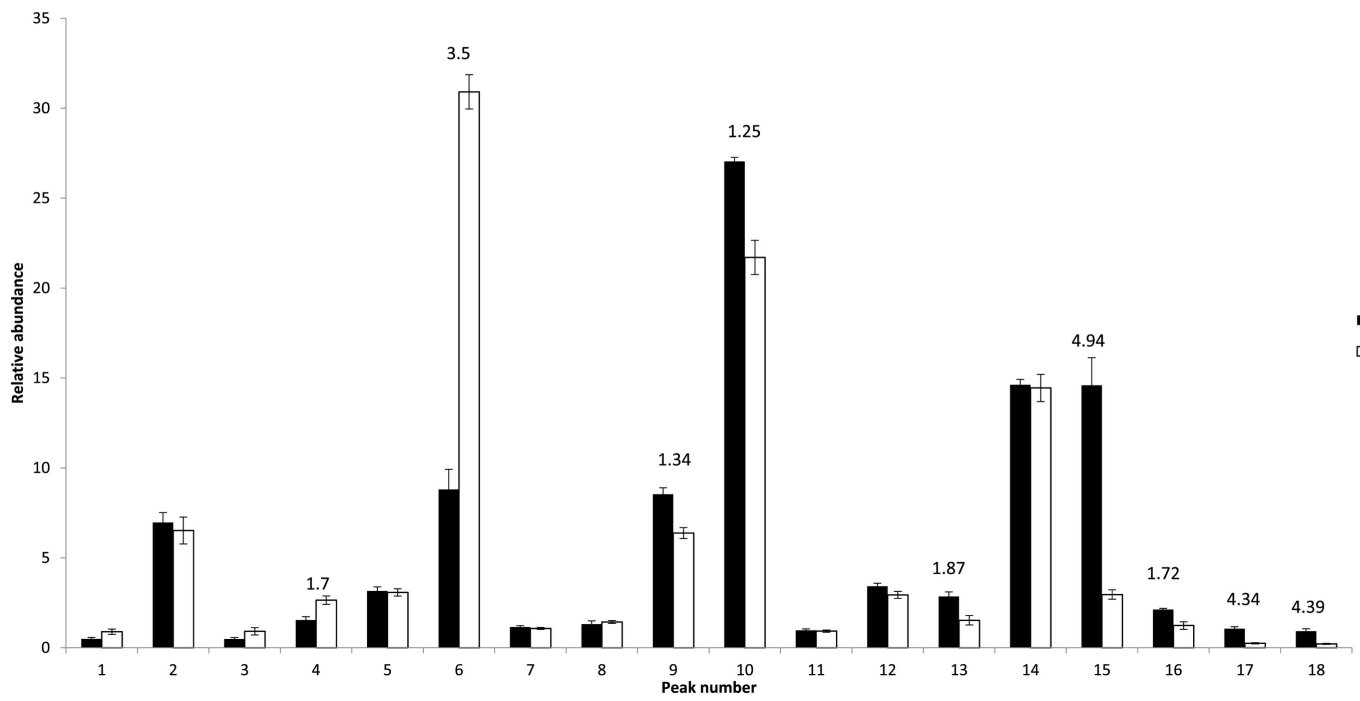

Figure 3 


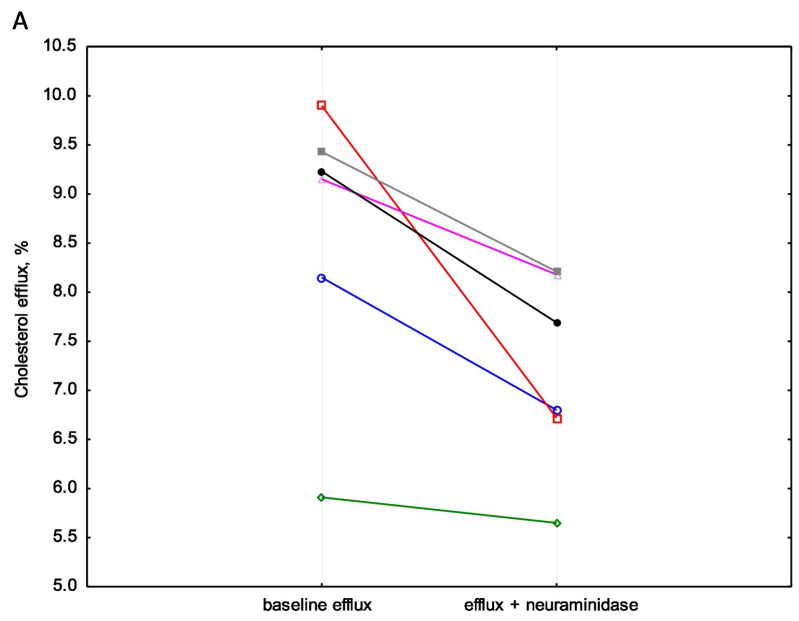

HDL

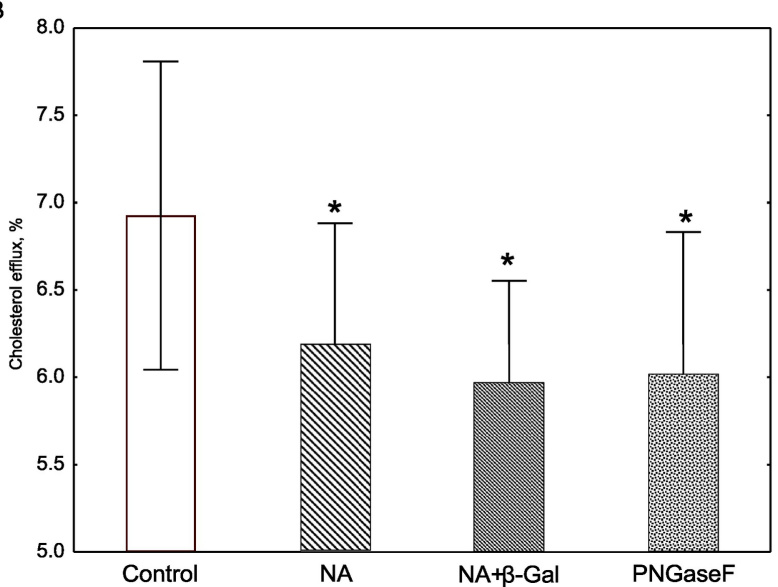

HDL

C

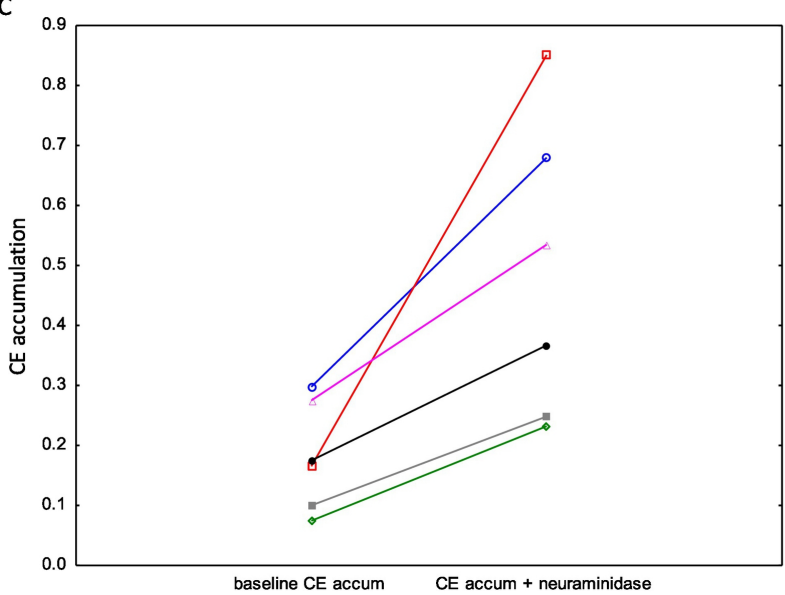

LDL

Figure 4 


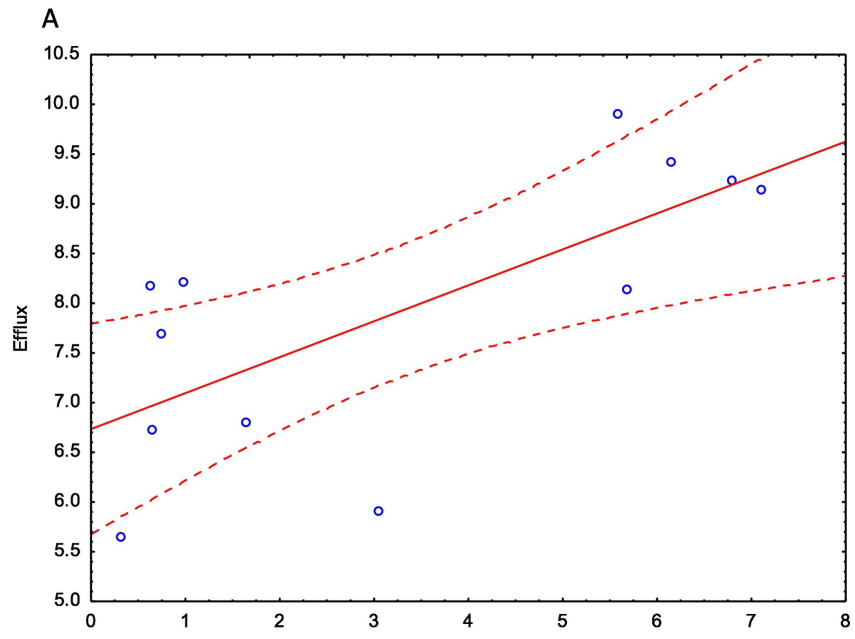

GPHDL13:Efflux: $r=0.7109, p=0.0095 ; r^{2}=0.5054$ L13

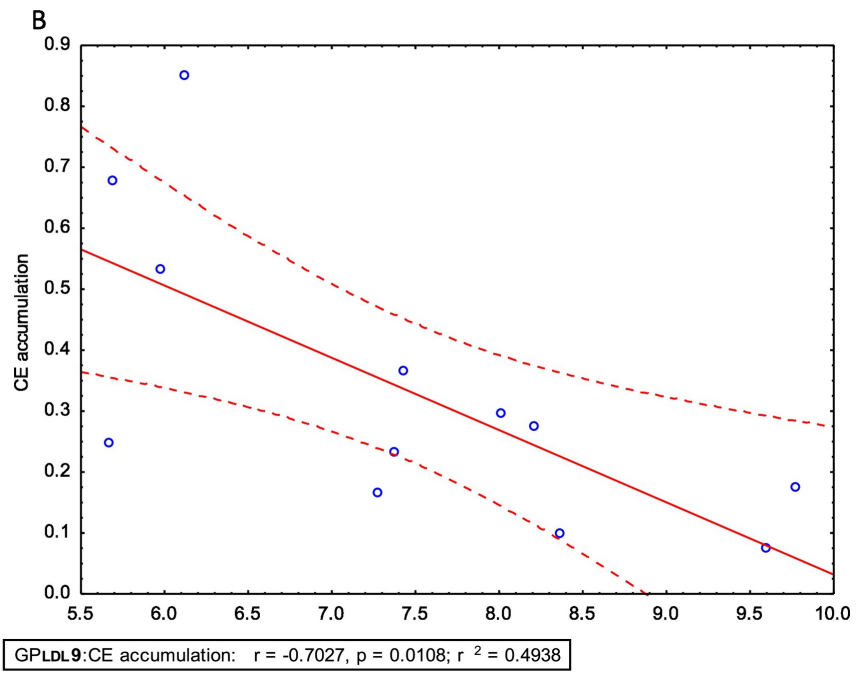

Figure 5 